\title{
Cigarette smoking and risk of non-Hodgkin lymphoma subtypes among women
}

\author{
LM Morton', TR Holford', B Leaderer', P Boyle ${ }^{2}$, SH Zahm ${ }^{3}$, Y Zhang', S Flynn ${ }^{4}$, G Tallini $^{4}$, B Zhang ${ }^{5}$, \\ PH Owens' and T Zheng ${ }^{*, I}$
}

'Department of Epidemiology and Public Health, Yale University School of Medicine, 129 Church Street, Suite 700, New Haven, CT O65I0, USA; ${ }^{2}$ Department of Epidemiology and Biostatistics, European Institute of Oncology, Milan 20 4 I, Italy; ${ }^{3}$ Division of Cancer Epidemiology and Genetics, National Cancer Institute, NIH, DHHS, Bethesda, MD 20892, USA; ${ }^{4}$ Department of Pathology, Yale University School of Medicine, New Haven, CT 06520, USA; ${ }^{5}$ Department of Epidemiology and Biostatistics, McGill University, Montreal 3, Canada H3A IA2

\begin{abstract}
Previous studies of the relationship between cigarette smoking and non-Hodgkin lymphoma (NHL) have yielded conflicting results, perhaps because most studies have evaluated the risk for all NHL subtypes combined. Data from a population-based case-control study conducted among women in Connecticut were used to evaluate the impact of cigarette smoking on the risk of NHL by histologic type, tumour grade, and immunologic type. A total of 601 histologically confirmed, incident cases of NHL and $7 / 8$ population-based controls provided in-person interviews. A standardised, structured questionnaire was used to collect information on each subject's current smoking status, age at initiation, duration and intensity of smoking, and cumulative lifetime exposure to smoking. Our data suggest that cigarette smoking does not alter the risk of all NHL subtypes combined. However, increased risk of follicular lymphoma appears to be associated with increased intensity and duration of smoking, and cumulative lifetime exposure to smoking. Compared with nonsmokers, women with a cumulative lifetime exposure of 16-33 pack-years and 34 pack-years or greater experience $50 \%$ increased risk $(O R=1.5,95 \% \mathrm{Cl} 0.9-2.5)$ and $80 \%$ increased risk $(\mathrm{OR}=1.8,95 \% \mathrm{Cl}$ ।. I - 3.2), respectively, of follicular lymphoma ( $P$ for linear trend $=0.05$ ). Our study findings are consistent with several previous epidemiologic studies suggesting that cigarette smoking increases the risk of follicular lymphoma. This research highlights the importance of distinguishing between $\mathrm{NHL}$ subtypes in future research on the aetiology of $\mathrm{NHL}$.
\end{abstract}

British Journal of Cancer (2003) 89, 2087-2092. doi: I0.I038/sj.bjc.660I 388 www.bjcancer.com

(c) 2003 Cancer Research UK

Keywords: lymphoma; non-Hodgkin; smoking; women; case-control studies

Over the past several decades, incidence rates of non-Hodgkin lymphoma (NHL) have increased dramatically in the United States and throughout the world (Hartge et al, 1994; Bray et al, 2001; Clarke and Glaser, 2002). The annual age-adjusted incidence rate of NHL in the US per 100000 persons rose from 8.9 in 1973 to 15.6 in 1999 (Ries et al, 2002). Despite this observed increase in NHL incidence and the intensification of epidemiologic investigations into the aetiology of NHL, few concrete risk factors have been identified for NHL.

Cigarette smoking has been proposed as one factor that could potentially increase the risk of NHL, although epidemiologic investigations of smoking and NHL have yielded conflicting results (Magnani et al, 1990; Brown et al, 1992; Linet et al, 1992; Tavani et al, 1994; Nelson et al, 1997; Zahm et al, 1997; Adami et al, 1998; De Stefani et al, 1998; Freedman et al, 1998; Herrinton and Friedman, 1998; Holly et al, 1999; Miligi et al, 1999; Grant, 2000; Parker et al, 2000; Fabbro-Peray et al, 2001; Peach and Barnett, 2001; Stagnaro et al, 2001; Besson et al, 2003). Three studies have

\footnotetext{
*Correspondence: Dr T Zheng; E-mail: tongzhang.zheng@yale.edu

This study was supported by grant CA62006-05 from the National Cancer Institute
}

Received 7 July 2003; revised 22 August 2003; accepted 17 September 2003 reported a statistically significant increased risk of NHL among smokers (Magnani et al, 1990; Linet et al, 1992; Freedman et al, 1998), while eight studies have reported no association or a weak association between cigarette smoking and NHL (Tavani et al, 1994; Nelson et al, 1997; Adami et al, 1998; De Stefani et al, 1998; Holly et al, 1999; Miligi et al, 1999; Grant, 2000; Fabbro-Peray et al, 2001).

A potential limitation of most previous studies of cigarette smoking and NHL may be that they have failed to investigate the effect of smoking by NHL subtype. Descriptive epidemiologic studies have shown that the magnitude of incidence rates and the recent changes in incidence rates vary for different NHL subtypes (Groves et al, 2000). Analytical epidemiologic studies have also shown that risk associated with various potential risk factors for NHL, such as pesticides, solvents, hair dye, and viruses, may vary by NHL subtype (Weisenburger, 1994; Germanidis et al, 1999; Shariff et al, 1999; Waddell et al, 2001; Zheng et al, 2002; Zhang et $a l$, in press). Earlier epidemiologic studies of smoking and NHL that have considered the association between cigarette smoking and NHL have also suggested that the relationship may vary by histologic subtype of NHL (Herrinton and Friedman, 1998; Parker et al, 2000; Stagnaro et al, 2001; Besson et al, 2003). Thus, evaluation of the potential impact of cigarette smoking on NHL by disease subtype appears to be necessary. 
Based on the inconsistent results of previous research, a population-based case-control study among 1319 Connecticut women was used to investigate the a priori hypothesis that smoking increases the risk of NHL, and that this increased risk varies by NHL histologic type, tumour grade, and immunologic type. The current status of smoking, age at initiation, duration and intensity of smoking, and cumulative lifetime exposure to smoking were compared between cases and controls to estimate the risk these factors confer on NHL and NHL subtypes.

\section{MATERIALS AND METHODS}

\section{Study population}

Detailed information on the study population and data collection for this study has been published elsewhere (Morton et al, in press). Briefly, a total of 1319 female residents of Connecticut, who were between the ages of 21 and 84 years, had no previous diagnosis of cancer (except nonmelanoma skin cancer), and were alive at the time of interview were recruited for this populationbased case-control study from 1995 to 2001. The Yale Comprehensive Cancer Center's Rapid Case Ascertainment Shared Resource (RCA), a component of the Connecticut Tumor Registry (CTR), was used to identify incident cases of NHL (ICD-O, M9590-9642, 9690-9701, 9740-9750). A total of 1122 potential NHL cases were identified, of which 290 were judged to be ineligible for this study (167 died before they could be interviewed, and 123 were excluded for other reasons, such as previous diagnosis of cancer, unable to speak English, or physician refusal). Thus, a total of 832 incident, eligible cases of NHL were contacted for participation in this study, and $601(72 \%)$ of these cases completed in-person interviews. The median time between diagnosis and interview for cases was 2.5 months. Two study pathologists (Drs Flynn, Tallini) independently reviewed the tissue samples for all cases to confirm the diagnosis of NHL and classify NHL cases according to the Working Formulation into histologic type (diffuse, follicular, other), tumour grade (low, intermediate, high, other), and immunologic type (B-cell, T-cell, other). Tissue samples receiving conflicting classifications were re-evaluated until a consensus was reached.

A population-based control group, consisting of 718 women who completed in-person interviews, was assembled using two methods. Random digit dialing was used to recruit women less than 65 years of age; including the initial telephone screening, $69 \%$ of the women contacted using random digit dialing completed in-person interviews. Women 65 years of age and older were selected randomly from the files of the Centers for Medicare and Medicaid Services; $47 \%$ of the women contacted from these files completed in-person interviews. The number of controls that were randomly selected within each age stratum was adjusted every few months in order to frequency match cases and controls by age in 5-year groups. A total of 718 controls completed in-person interviews.

\section{Data collection}

This study was conducted based on a protocol approved by the Human Investigations Committees at Yale University and the Connecticut Department of Health, and an Institutional Review Board of the National Cancer Institute. Cases were contacted first by letter and then by telephone, only after approval by each subject's physician. Controls were contacted after selection through random sampling. Trained interviewers administered a standardised, structured questionnaire to subjects who agreed to participate. During the interview, respondents were asked about their smoking history and other known or suspected risk factors for NHL.
Subjects were classified as never smokers if they had never smoked at least 100 cigarettes prior to 1 year before the interview. Respondents who had smoked at least 100 cigarettes were further questioned as to the age they began smoking, the average number of cigarettes smoked per day, the number of years during which they smoked at least one cigarette per day, whether they had stopped smoking in the past year, and the age at which they stopped smoking. Additional information on age, height, usual weight, education, race, alcohol use, menopausal status, family history of cancer, and other factors was also obtained during the interview. Continuous demographic variables and potential confounding factors were categorised a priori, based on previous cutpoints used in the literature or the distribution among control subjects.

\section{Statistical analysis}

Statistical analyses for this study were performed using the SAS system, version 8.02. (SAS Institute Inc., Cary, NC, USA). Unconditional logistic regression models were developed using data on smoking history, in order to predict the risk of NHL and NHL subtypes (Breslow and Day, 1980). Subjects who reported smoking less than a total of 100 cigarettes in their lifetime were classified as never smokers, and were used as the reference group for all analyses. Ever smokers were further categorised as current or former smokers, based on their smoking status at the time of the interview. Data on the duration and intensity of smoking were integrated to create a single measure (pack-years $=$ number of packs smoked per day times number of years smoked), in order to estimate the cumulative lifetime exposure to cigarette smoking. Continuous predictor variables, including age started smoking, duration of smoking, number of cigarettes smoked per day, and pack-years, were categorised into tertiles or quartiles a priori, based on previous cutpoints used in the literature or the distribution among control subjects.

Age, race, family history of cancer, education, body-mass index (BMI), alcohol use, and menopausal status were considered as potential confounding factors for this analysis. The associations of potential confounding factors with smoking predictor variables and NHL subtypes were assessed using Pearson's $\chi^{2}$ statistic. Wald $\chi^{2}$ statistics were calculated for each potential confounder in the multivariate models to test the null hypothesis that each covariate had no effect on the outcome, given that the other variables were already in the model. Decisions on which covariates to include in the final model were based on a Wald $\chi^{2}$ statistic with $P<0.2$ and a greater than $10 \%$ change in the risk estimates for at least some NHL subtypes. The final estimates of the risk of NHL and NHL subtypes using the smoking predictor variables were adjusted for age $(<50,50-70,>70$ years), race (white, other), family history of cancer (any cancer, none), education (high school or less, some college, college graduate or more), BMI ( $<25,25-29.99$, $\geqslant 30 \mathrm{~kg} \mathrm{~m}^{-2}$ ), alcohol use (ever, never), and menopausal status (premenopausal, postmenopausal). Adjusted odds ratios (OR) and $95 \%$ confidence intervals $(95 \% \mathrm{CI})$ were calculated using multivariate unconditional logistic regression models. Tests for linear trend were conducted by including smoking predictor variables as continuous variables in the multivariate unconditional logistic regression models.

\section{RESULTS}

The selected demographic characteristics of cases and controls were compared (Table 1). Owing to the frequency matching by age strata, cases and controls were similar with respect to age. The distribution of race and reported family history of cancer were also similar among cases and controls. For all NHL cases combined and 
Table I Selected characteristics of NHL cases and controls among women from Connecticut

\begin{tabular}{|c|c|c|}
\hline & $\begin{array}{l}\text { Percent of cases } \\
\quad(n=601)\end{array}$ & $\begin{array}{l}\text { Percent of controls } \\
\quad(n=7 \mid 8)\end{array}$ \\
\hline \multicolumn{3}{|l|}{ Age (years) } \\
\hline$\leqslant 45$ & 12.3 & 15.9 \\
\hline $46-55$ & 19.3 & 18.9 \\
\hline $56-65$ & 20.6 & 19.9 \\
\hline $66-75$ & 28.6 & 25.9 \\
\hline$\geqslant 76$ & 19.1 & 19.4 \\
\hline \multicolumn{3}{|l|}{ Race } \\
\hline White & 95.3 & 94.3 \\
\hline Other & 4.7 & 5.7 \\
\hline \multicolumn{3}{|l|}{ Family history } \\
\hline None & 21.5 & 24.9 \\
\hline Any Cancer & 78.5 & 75.1 \\
\hline \multicolumn{3}{|l|}{ Education } \\
\hline High school or less & 43.4 & 37.0 \\
\hline Some college & 32.9 & 30.8 \\
\hline College graduate or more & 23.6 & 32.2 \\
\hline \multicolumn{3}{|l|}{ BMI $\left(\mathrm{kg} \mathrm{m}^{-2}\right)$} \\
\hline$<25$ & 49.8 & 56.5 \\
\hline $25-29.99$ & 31.6 & 27.9 \\
\hline$\geqslant 30$ & 18.6 & 15.6 \\
\hline \multicolumn{3}{|l|}{ Alcohol use } \\
\hline Never & 38.3 & 32.5 \\
\hline Ever & 61.7 & 67.5 \\
\hline
\end{tabular}

across most NHL subtypes (data not shown), cases tended to be less highly educated and have a higher BMI than controls $(P<0.05)$. In addition, fewer cases than controls reported ever having consumed alcohol $(P<0.05)$.

Table 2 presents the risk of NHL by smoking for all NHL subtypes combined. When compared to women who have never smoked, the risk of NHL did not appear to be significantly altered by current or former smoking status, the age subjects began smoking, the number of cigarettes smoked per day, the duration of smoking, or the cumulative lifetime exposure to smoking (Table 2).

Further analysis by NHL subtype, however, suggests that the risk of follicular lymphoma may be elevated by increased duration of smoking and cumulative lifetime exposure to smoking (Table 3 ). Compared with nonsmokers, women with a cumulative lifetime exposure of 16-33 pack-years and 34 pack-years or greater experience $50 \%$ increased risk $(\mathrm{OR}=1.5,95 \% \mathrm{CI} 0.9-2.5)$ and $80 \%$ increased risk $(\mathrm{OR}=1.8,95 \% \mathrm{CI} 1.1-3.2)$, respectively, illustrating a dose-response relationship between cumulative lifetime exposure and follicular lymphoma $(P$ for linear trend $=0.05)$. Our data fail to show clear relationships with the intensity of smoking, the age subjects began smoking, and current smoking status, although this is not surprising given the small number of cases examined if the relationship with smoking is weak. Stratification by age for those aged less than 65 years or 65 years and over showed similar results.

Smoking history does not appear to alter the risk of NHL by tumour grade (low, medium, high) or for B-cell lymphomas (Table 3). There is a suggestion of an association for T-cell lymphomas; however, the number of cases was too small to conclusively assess the impact of smoking. Smoking did not significantly alter the risk of NHL for other histologic types, tumour grades, and immunologic types, as classified by the Working Formulation (data not shown).
Table 2 Risk of NHL associated with cigarette smoking for all NHL cases combined

\begin{tabular}{|c|c|c|c|c|}
\hline & $\begin{array}{c}\text { Cases } \\
\#\end{array}$ & $\begin{array}{c}\text { Controls } \\
\#\end{array}$ & $\mathbf{O R}^{\mathbf{a}}$ & $95 \% \mathrm{Cl}$ \\
\hline \multicolumn{5}{|l|}{ Smoking } \\
\hline Never & 270 & 323 & 1.0 & \\
\hline Ever & 331 & 395 & 1.0 & $(0.8,1.3)$ \\
\hline Current & 77 & 106 & 0.9 & $(0.6,1.2)$ \\
\hline Former & 254 & 289 & I.1 & $(0.8,1.4)$ \\
\hline \multicolumn{5}{|l|}{ Age at initiation (years) } \\
\hline$\leqslant 15$ & 74 & 89 & 1.0 & $(0.7,1.5)$ \\
\hline $16-19$ & 163 & 187 & 1.1 & $(0.8,1.4)$ \\
\hline$\geqslant 20$ & 94 & 119 & 1.0 & $(0.7,1.3)$ \\
\hline$P$ for linear trend & & & 0.97 & \\
\hline \multicolumn{5}{|l|}{ Intensity (\# cig/day) } \\
\hline $1-10$ & 73 & 100 & 1.0 & $(0.7,1.3)$ \\
\hline $11-15$ & 83 & 104 & 1.0 & $(0.7,1.4)$ \\
\hline $16-20$ & 119 & 135 & 1.0 & $(0.8,1.4)$ \\
\hline$>20$ & 56 & 56 & 1.2 & $(0.8,1.7)$ \\
\hline$P$ for linear trend & & & 0.32 & \\
\hline \multicolumn{5}{|l|}{ Duration (years) } \\
\hline $1-10$ & 50 & 72 & 0.9 & $(0.6,1.4)$ \\
\hline $11-20$ & 62 & 90 & 0.9 & $(0.6,1.3)$ \\
\hline $21-30$ & 69 & 80 & 1.0 & $(0.7,1.5)$ \\
\hline$>30$ & 150 & 153 & 1.2 & $(0.9,1.5)$ \\
\hline$P$ for linear trend & & & 0.45 & \\
\hline \multicolumn{5}{|l|}{ Pack-years } \\
\hline $1-7$ & 81 & 103 & 1.0 & $(0.7,1.5)$ \\
\hline $8-14$ & 53 & 95 & 0.7 & $(0.5,1.0)$ \\
\hline $15-33$ & 94 & 104 & 1.1 & $(0.8,1.5)$ \\
\hline$\geqslant 34$ & 103 & 93 & 1.3 & $(0.9,1.8)$ \\
\hline$P$ for linear trend & & & 0.18 & \\
\hline
\end{tabular}

${ }^{a}$ Adjusted for age, race, family history of any cancer, education, BMI, previous alcohol use, and menopausal status.

\section{DISCUSSION}

In this population-based case-control study, we found that smoking appeared to increase the risk of follicular lymphoma, and that this risk increased with increased duration and packyears of cigarette smoking. Smoking did not appear to play a role in other histologic types of NHL.

Our results are consistent with previous epidemiologic studies that also considered the relationship between cigarette smoking and NHL by histologic subtype, and that found an increased risk among smokers for follicular lymphoma, but not for diffuse lymphoma (Herrinton and Friedman, 1998; Parker et al, 2000; Stagnaro et al, 2001; Besson et al, 2003). In a population-based case-control study conducted in Italy, smoking was associated with increased risk of follicular lymphoma, particularly among women (Stagnaro et al, 2001). That study reported approximately two-fold increased risk among women with the longest duration of smoking; however, the trend for intensity of smoking was less clear, and the impact of cumulative lifetime exposure to cigarette smoking was not evaluated. A hospital-based case-control study among men and women in France suggested a three-fold increase in the risk of follicular NHL among current smokers, although the result was not statistically significant, perhaps due to the small sample size (Besson et al, 2003). Two cohort studies, the Iowa Women's Health Study (Parker et al, 2000) and a cohort study of men and women from California (Herrinton and Friedman, 1998), also have reported approximately two-fold increased risk of follicular lymphoma among smokers compared to nonsmokers, 
Table 3 Risk of NHL associated with cigarette smoking for $\mathrm{NHL}$ subtypes

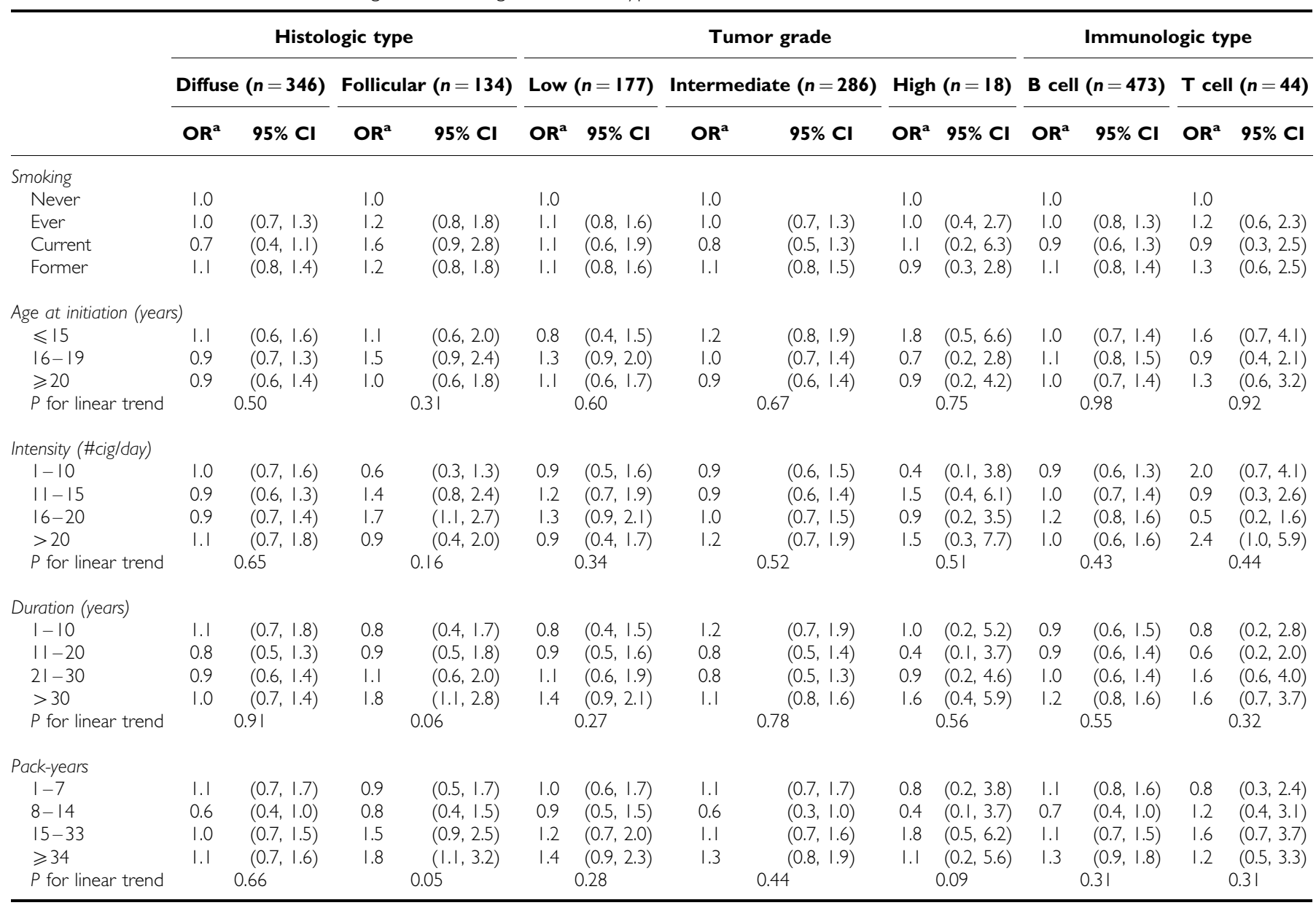

${ }^{a}$ Adjusted for age, race, family history of any cancer, education, BMI, previous alcohol use, and menopausal status.

although these estimates were based on very few cases. Our study and the three studies discussed above all found that a history of cigarette smoking is associated with an approximately two-fold or greater increased risk of follicular lymphoma when compared to nonsmokers, but no relationship was found between smoking and other NHL subtypes.

Previous studies that did not investigate the relationship between smoking and NHL by histologic subtype may not have found a relationship because smoking seems to increase only the risk of follicular lymphoma, but not other NHL subtypes. If we had not stratified by histologic type, the results of this study would have been consistent with previous studies that did not stratify and showed no effect.

It is not clear why the relationship between smoking and NHL only exists for follicular lymphoma and not for other subtypes of NHL. The mechanism of follicular lymphoma development among cigarette smokers is not known. Studies have shown that approximately $80-90 \%$ of follicular lymphomas, regardless of cell type, are positive for $\mathrm{t}(14 ; 18)$ translocation (Cleary et al, 1986a, b). This somatic mutation joins the bcl-2 gene on chromosome 18 to the immunoglobulin heavy chain gene on chromosome 14, increasing the production of bcl-2 protein, which is involved in the inhibition of apoptosis (Cleary et al, 1986a,b). Since these mutations are likely to be the result of a direct carcinogenic effect, rather than being related to immune suppression, it is possible that the carcinogenic compounds in cigarettes could play a role in these mutations. A recent case-control study of NHL that classified cases by this mutation suggested a potential increased risk among cigarette smokers for $t(14 ; 18)$-positive NHL but not for $t(14 ; 18)$ negative NHL, although no clear trend was observed (Schroeder et al, 2002). Additional studies considering the role of this mutation could help to elucidate the role of cigarette smoking in the development of follicular lymphomas.

A number of strengths and limitations of this study should be considered in the interpretation of the results. In this large, population-based case-control study, trained interviewers used in-person, standardised, and structured interviews to minimise the information bias resulting from exposure misclassification. Incident cases were histologically confirmed and categorised according to the Working Formulation, in order to minimise the information bias resulting from disease misclassification. In addition, subjects were asked standard, detailed questions with respect to their smoking history, so that the smoking status, the age subjects began smoking, the intensity and duration of smoking, and the lifetime cumulative exposure to cigarette smoke could be evaluated separately to understand which aspect of cigarette smoking, if any, affects the risk of NHL and NHL subtypes. Despite the relatively large size of this study, however, stratification limited our ability to estimate the impact of smoking on the risk of high-grade tumours and T-cell lymphomas, which account for only a small proportion of lymphomas. In addition, this analysis only addresses the potential relationship between smoking and NHL for women, because one of the main objectives of this population-based case-control study was to investigate the 
relationship between hair dye use, female reproductive history, and menarche and risk of NHL in Connecticut women.

Although this study was population-based, the relatively low participation rates among potential population controls, especially among women 65 years of age and older, recruited from the files of the Centers of Medicare and Medicaid Services, are of possible concern. However, the association between smoking and disease was observed only among women with follicular lymphomas and not other NHL subtypes. In addition, stratification by age for those aged less than 65 years or 65 years and over showed similar results. Therefore, it is unlikely that selection bias can explain the observed associations. Self-report of smoking history has been shown to be reliable and accurate, based on comparisons of selfreported data to biochemical markers of tobacco exposure (Patrick et al, 1994). Therefore, it is unlikely that the observed result is due to recall bias. The hypothesised relationship between smoking and NHL is not well known; therefore it is unlikely that the observed result is due to reporting bias. In addition, the elevated risk of follicular lymphoma is unlikely to be the result of recall or reporting bias because the association is not observed across all NHL subtypes.

In summary, this population-based case-control study supports the hypothesis that increased pack-years and duration of smoking result in an elevated risk of follicular lymphoma, but do not alter

\section{REFERENCES}

Adami J, Nyren O, Bergstrom R, Ekbom A, Engholm G, Englund A, Glimelius B (1998) Smoking and the risk of leukemia, lymphoma, and multiple myeloma (Sweden). Cancer Causes Control 9(1): 49-56

Besson H, Renaudier P, Merrill RM, Coiffier B, Sebban C, Fabry J, Trepo C, Sasco AJ (2003) Smoking and non-Hodgkin's lymphoma: a case-control study in the Rhône-Alpes region of France. Cancer Causes Control 14(4): $381-389$

Bray I, Brennan P, Boffetta P (2001) Recent trends and future projections of lymphoid neoplasms - a Bayesian age-period-cohort analysis. Cancer Causes Control 12(9): 813-820

Breslow NE, Day NE (1980) Statistical Methods in Cancer Research, Vol. I The Analysis of Case-Control Studies. Lyon: International Agency for Research on Cancer (IARC Scientific Publications No. 32)

Brown LM, Everett GD, Gibson R, Burmeister LF, Schuman LM, Blair A (1992) Smoking and risk of non-Hodgkin's lymphoma and multiple myeloma. Cancer Causes Control 3: 49-55

Clarke CA, Glaser SL (2002) Changing incidence of non-Hodgkin lymphomas in the United States. Cancer 94(7): 2015-2023

Cleary ML, Galili N, Sklar J (1986a) Detection of a second $t(14 ; 18)$ breakpoint cluster region in human follicular lymphomas. $J$ Exp Med 164: $315-320$

Cleary ML, Smith SD, Sklar J (1986b) Cloning and structural analysis of cDNAs for bcl-2 and a hybrid bcl-2/immunoglobulin transcript resulting from the $\mathrm{t}(14 ; 18)$ translocation. Cell 47: 19-28

De Stefani E, Fierro L, Barrios E, Ronco A (1998) Tobacco, alcohol, diet and risk of non-Hodgkin's lymphoma: a case-control study in Uruguay. Leuk Res 22: $445-452$

Fabbro-Peray P, Daures JP, Rossi JF (2001) Environmental risk factors for non-Hodgkin's lymphoma: a population-based case-control study in Languedoc-Roussillon, France. Cancer Causes Control 12: $201-212$

Freedman DS, Tolbert PE, Coates R, Brann EA, Kjeldsberg CR (1998) Relation of cigarette smoking to non-Hodgkin's lymphomas among middle-aged men. Am J Epidemiol 148: 833 -841

Germanidis G, Haioun C, Pourquier J, Gaulard P, Pawlotsky JM, Dhumeaux D, Reyes F (1999) Hepatitis C virus infection in patients with overt B-cell non-Hodgkin's lymphoma in a French center. Blood 93: 1778-1779, (letter)

Grant WB (2000) Ecological study of dietary and smoking links to lymphoma. Altern Med Rev 5: 563-572

Groves FD, Linet MS, Travis LB, Devesa SS (2000) Cancer surveillance series: non-Hodgkin's lymphoma incidence by histologic subtype in the United States from 1978 through 1995. J Natl Cancer Inst 92(15): $1240-1251$ the risk for other NHL subtypes. The results of this study highlight the need to distinguish between NHL histologic subtypes in future research on the aetiology of NHL.

\section{ACKNOWLEDGEMENTS}

Certain data used in this study were obtained from the Connecticut Tumor Registry of the Connecticut Department of Public Health. We assume full responsibility for the analyses and interpretation of these data. We thank the institutions that allowed access to diagnostic materials and pathology reports, including the following hospitals: Charlotte Hungerford Hospital, Danbury Hospital, Greenwich Hospital, Griffin Hospital, Hartford Hospital, Johnson Memorial Hospital, Middlesex Hospital, Lawrence and Memorial Hospital, New Britain General Hospital, Bradley Memorial Hospital, Norwalk Hospital, St Francis Hospital and Medical Center, St Mary's Hospital, Hospital of St Raphael, St Vincent's Medical Center, Stamford Hospital, William W Backus Hospital, Waterbury Hospital, Yale-New Haven Hospital, Manchester Memorial Hospital, Rockville General Hospital, Bridgeport Hospital, Windham Hospital, Sharon Hospital, Milford Hospital, New Milford Hospital, Bristol Hospital, MidState Medical Center, and Day-Kimball Hospital.
Hartge P, Devesa SS, Fraumeni Jr JF (1994) Hodgkin's and Non-Hodgkin's lymphomas. Cancer Surv 19/20: $423-453$

Herrinton LJ, Friedman GD (1998) Cigarette smoking and risk of nonHodgkin's lymphoma subtypes. Cancer Epidemiol Biomarkers Prev 7: $25-28$

Holly EA, Lele C, Bracci PM, McGrath MS (1999) Case-control study of non-Hodgkin's lymphoma among women and heterosexual men in the San Francisco Bay Area, California. Am J Epidemiol 150: 375 - 389

Linet MS, McLaughlin JK, Hsing AW, Wacholder S, Co Chien HT, Schuman LM, Bjelke E, Blot WJ (1992) Is cigarette smoking a risk factor for nonHodgkin's lymphoma or multiple myeloma? Results from the Lutheran Brotherhood cohort study. Leuk Res 16: 621-624

Magnani C, Pastore G, Luzzatoo L, Terracini B (1990) Parental occupation and other environmental factors in the etiology of leukemias and nonHodgkin's lymphomas in childhood: a case-control study. Tumori 76: $413-419$

Miligi L, Seniori Costantini A, Crosignani P, Fontana A, Masala G, Nanni O, Ramazzotti V, Rodella S, Stagnaro E, Tumino R, Vigano C, Vindigni C, Vineis P (1999) Occupational, environmental, and life-style factors associated with the risk of hematolymphopoietic malignancies in women. Am J Ind Med 36(1): 60-69

Morton LM, Holford TR, Leaderer B, Zhang Y, Zahm SH, Boyle P, Flynn S, Tallini G, Owens PH, Zhang B, Zheng T (in press). Alcohol use and risk of non-Hodgkin lymphoma among Connecticut women. Cancer Causes Control

Nelson RA, Levine AM, Marks G, Bernstein L (1997) Alcohol, tobacco and recreational drug use and the risk of non-Hodgkin's lymphoma. $\mathrm{Br} J$ Cancer 76: $1532-1537$

Parker AS, Cerhan JR, Dick F, Kemp J, Habermann TM, Wallace RB, Sellers TA, Folsom AR (2000) Smoking and risk of non-Hodgkin lymphoma subtypes in a cohort of older women. Leuk Lymphoma 37: 341-349

Patrick DL, Cheadle A, Thompson DC, Diehr P, Koepsell T, Kinne S (1994) The validity of self-reported smoking: a review and meta-analysis. Am J Public Health 84(7): $1086-1093$

Peach HG, Barnett NE (2001) Critical review of epidemiological studies of the association between smoking and non-Hodgkin's lymphoma. Hematol Oncol 19: 67-80

Ries LAG, Eisner MP, Kosary CL, Hankey BF, Miller BA, Clegg L, Edward BK (2002), SEER Cancer Statistics Review, 1973-1999. National Cancer Institute, accessed August 2002

Schroeder JC, Olshan AF, Baric R, Dent GA, Weinberg CR, Yount B, Cerhan JR, Lynch CF, Schuman LM, Tolbert PE, Rothman N, Cantor KP, Blair A (2002) A case-control study of tobacco use and other non-occupational 
risk factors for $\mathrm{t}(14 ; 18)$ subtypes of non-Hodgkin's lymphoma (United States). Cancer Causes Control 13: 159-168

Shariff S, Yoshida EM, Gascoyne RD, Le N, Connors JM, Middleton PJ, Shenkier TN (1999) Hepatitis C virus infection and B-cell non-Hodgkin's lymphoma in British Columbia: a cross-sectional analysis. Ann Oncol 10: 961-964

Stagnaro E, Ramazzotti V, Crosignani P, Fontana A, Masal G, Miligi L, Nanni O, Neri M, Rodella S, Costantini AS, Tumino R, Vigano C, Vindigni C, Vineis P (2001) Smoking and hematolymphopoietic malignancies. Cancer Causes Control 12: 325-334

Tavani A, Negri E, Franceschi S, Serraino D, La Vecchia C (1994) Smoking habits and non-Hodgkin's lymphoma: a case-control study in Northern Italy. Prev Med 23: 447-452

Waddell BL, Zahm SH, Baris D, Weisenburger DD, Holmes F, Burmeister LF, Cantor KP, Blair A (2001) Agricultural use of organophosphate pesticides and the risk of non-Hodgkin's lymphoma among male farmers (United States). Cancer Causes Control 12(6): 509-517

Weisenburger DD (1994) Epidemiology of non-Hodgkin's lymphoma: recent findings regarding an emerging epidemic. Ann Oncol 5(Suppl 1): $19-24$

Zahm SH, Weisenburger DD, Holmes FF, Cantor KP, Blair A (1997) Tobacco and non-Hodgkin's lymphoma: combined analysis of three case-control studies. Cancer Causes Control 8: 159-166

Zhang Y, Holford T, Leaderer B, Boyle P, Zahm SH, Flynn S, Tallini G, Owens $\mathrm{PH}$, Zheng $\mathrm{T}$ (in press). Hair coloring product use and risk of non-Hodgkin's lymphoma: a population-based case-control study in Connecticut. Am J Epidemiol

Zheng T, Blair A, Zhang Y, Weisenburger DD, Zahm SH (2002) Occupation and risk of non-Hodgkin's lymphoma and chronic lymphocytic leukemia. J Occup Environ Med 44(5): 469-474 